\title{
Near-road air quality monitoring: Factors affecting network design and interpretation of data
}

\author{
R. Baldauf $\cdot$ N. Watkins $\cdot$ D. Heist $\cdot$ C. Bailey $\cdot$ \\ P. Rowley $\cdot$ R. Shores
}

Received: 4 September 2008 / Accepted: 9 February 2009/Published online: 12 March 2009

(C) The Author(s) 2009. This article is published with open access at Springerlink.com

\begin{abstract}
The growing number of health studies identifying adverse health effects for populations spending significant amounts of time near large roadways has increased the interest in monitoring air quality in this microenvironment. Designing near-road air monitoring networks or interpreting previously collected near-road monitoring data is essential for transportation system planning, environmental impact assessments, and exposure assessments in health studies. For these applications, care must be taken in determining the pollutants of interest for both air quality and health assessments. In addition, planners and data analysts need to evaluate and understand the potential influence of the roadway type, design, and presence of roadside structures on the potential
\end{abstract}

R. Baldauf $\cdot$ C. Bailey $\cdot$ P. Rowley

Office of Air and Radiation, Office of Transportation and Air Quality, National Vehicle and Fuel Emissions Laboratory,

U.S. Environmental Protection Agency,

Ann Arbor, MI, USA

R. Baldauf $\cdot$ R. Shores

Office of Research and Development, National Risk Management Research Laboratory, U.S. Environmental Protection Agency, Research Triangle Park, NC, USA

N. Watkins

Office of Air and Radiation, Office of Air Quality Planning and Standards, U.S. Environmental Protection Agency,

Research Triangle Park, NC, USA

D. Heist

Office of Research and Development, National Exposure Research Laboratory, U.S. Environmental Protection Agency, Research Triangle Park, NC, USA

R. Baldauf $(\bowtie)$

U.S. Environmental Protection Agency,

109 T.W. Alexander Dr., NC 27711, USA

e-mail: Baldauf.Richard@epa.gov transport and dispersion of traffic-emitted pollutants on these air quality and health evaluations. This paper summarizes key factors related to the collection and interpretation of near-road air quality data from the perspective of the pollutants of interest and the location of the monitoring sites.

Keywords Air quality $\cdot$ Health studies · Monitoring network design $\cdot$ Near-road $\cdot$ Traffic emissions

\section{Introduction}

In recent years, a large number of epidemiological studies have examined associations between living near major roads and adverse health endpoints. These studies indicate that populations living, working, or going to school near major roads may be subjected to an increased risk for a number of adverse health effects, including respiratory, cardiovascular, premature mortality, birth and developmental effects, and cancer (e.g., Pearson et al. 2000; Wilhelm and Ritz 2003; Finkelstein et al. 2004; Gauderman et al. 2005; McConnell et al. 2006; Adar and Kaufman 2007; Samet 2007; Samal et al. 2008). Air quality monitoring studies have measured elevated concentrations of pollutants emitted directly by motor vehicles near large roadwaysrelative to overall urban background concentrationsalthough these studies have been for short durations (e.g., Zhu et al 2002; Harrison et al. 2003; Reponen et al. 2003; Kim et al. 2004; Baldauf et al. 2008a). These elevated concentrations generally occur within a few hundred meters of the road; however, this distance may vary depending on the traffic patterns, environmental conditions, topography, and the presence of roadside structures.

The referenced health studies examining near-road populations generally employed non-specific metrics to 
represent exposures to traffic-generated pollutants. Typical exposure metrics include distance to the nearest road, traffic volume on the nearest roads [usually as the average annual daily traffic (AADT) count], or a summary measure of total traffic density within a specified area around the residence/ school/workplace. The desire to better understand the relationship between exposure and health effects necessitates establishing longer term near-road air quality monitoring capabilities, as well as interpreting historical monitoring data for air quality and health assessments.

This paper summarizes important factors to be considered in designing near-road air quality monitoring networks or interpreting previously collected data. These factors are becoming increasingly important in designing an ambient air monitoring strategy, especially in the USA, as federal and state, local, and tribally run networks change to adapt to new National Ambient Air Quality Standards (NAAQS) requirements and evolving monitoring objectives. This paper presents options and considerations for specific pollutants and monitoring techniques, addresses the evaluation of near-road air pollutant impacts (including siting logistics and concerns), evaluates the effects of roadside structures on pollutant transport and dispersion, and describes issues related to the spatial extent of monitoring air pollutants near roads.

\section{Measurements}

Collecting and interpreting near-road air quality measurements requires information on source characteristics as well as on the resulting air pollutant concentrations. The air pollutants measured should be chosen based on the emission characteristics of motor vehicles as well as potential public health concerns. The following sections discuss potential parameters and pollutants of interest for near-road monitoring.

\section{Traffic activity}

Important parameters for traffic activity that can be readily obtained for near-road monitoring assessments include the number of vehicles, the fleet mix, and vehicle speeds. Each of these parameters has an effect on the concentration and characteristics of near-road pollutants. Traffic volume provides information on the overall source input. The fleet mix indicates the role of vehicle type on near-road air quality; for example, emissions can be quite different for locations where light-duty passenger vehicles primarily burn gasoline than where heavy-duty trucks primarily burn diesel. Speed provides an indication of the type of operation on the highway when compared to traffic volumes; for example, low speeds with higher traffic volumes often indicate road congestion, while high speeds with lower volumes suggest relatively little congestion.

Around the world, many national and state transportation agencies maintain a network of traffic surveillance equipment ranging from external devices, such as video cameras and radar, to instruments embedded in the road pavement, including weigh-in-motion sensors. Prior to selecting the site for a near-road monitoring study, the researcher should contact the appropriate transportation agencies to identify the locations of their monitoring systems in order to leverage the existing traffic monitoring infrastructure and maximize the amount of data for use in the study. Air quality monitoring close to an existing traffic surveillance site will provide valuable information for interpreting the relationship between the air quality measurements and emissions from traffic operations. If a traffic monitoring site is not available, the installation of traffic surveillance equipment should be considered, if feasible.

\section{Meteorology}

Meteorological measurements, namely wind speed and direction, temperature, humidity, and atmospheric stability, are needed for interpreting near-road air quality data. According to Venkatram et al. (2007), the most important factors driving the dispersion of traffic-generated emissions are wind speed and wind direction; in particular, the standard deviation of the vertical fluctuation in wind. An important factor in near-road air quality measurements is the influence of moving traffic on wind-flow fields near the road. This "vehicle-induced turbulence" can extend tens of meters from the road (Kalthoff et al. 2005). As a result, conducting meteorological measurements at the air quality monitoring site should be strongly considered. Since vehicle-induced turbulence has a horizontal and vertical effect, measurements collected at multiple heights and in the horizontal and vertical components are most useful for comparing general air mass flow from the road with vehicle-induced turbulence. In addition to these local wind flow and turbulence measurements, data on other parameters, such as temperature and relative humidity, will still be important since these parameters affect the generation, transformation, and transport of pollutants emitted by motor vehicles.

Air quality

Air quality measurement considerations include both the types of pollutants monitored as well as the location of these measurements. This section focuses on the types of pollutants of interest for near-road monitoring, including criteria pollutants (those with NAAQS), air toxics, and select particulate matter (PM) components. When new 
monitoring networks are being designed, the ultimate choice of pollutants to be measured depends on the overall objective of the monitoring site(s). The following sections discuss potential compounds of interest, with the aim of facilitating the selection process, and the surrogate measurements that can assist in interpreting traffic emission impacts on near-road air quality and human health effects.

\section{Criteria pollutants}

For this paper, criteria pollutants include compounds that are covered by the NAAQS in the USA and the air quality guidelines of the World Health Organization (WHO). Nearroad monitoring can be carried out to assess the impacts of transportation systems on local air quality pollutant concentrations, evaluate motor vehicle emission control programs, and elucidate the (negative) impacts of transportation sources on local human health and/or the environment.

Carbon monoxide Motor vehicles significantly contribute to ambient carbon monoxide (CO) concentrations. Although $\mathrm{CO}$ emissions from motor vehicles have declined through emission control technologies and regulations in many countries, motor vehicles remain the primary source of this pollutant in most locations. All motor vehicles emit $\mathrm{CO}$, but the majority of $\mathrm{CO}$ emitted from this source occurs from light-duty, gasoline-powered vehicles. In addition to health concerns from $\mathrm{CO}$ exposures, $\mathrm{CO}$ may be a useful indicator of the transport and dispersion of inert, primary combustion emissions from traffic sources since $\mathrm{CO}$ does not react in the near-road environment.

Oxides of nitrogen Motor vehicles also significantly contribute to ambient nitrogen oxides $\left(\mathrm{NO}_{\mathrm{x}}\right)$ emissions in most countries. Although all motor vehicles emit $\mathrm{NO}_{\mathrm{x}}$, the majority of on-road emissions occur from diesel vehicles. In terms of primary emissions, the majority of $\mathrm{NO}_{\mathrm{x}}$ exhaust is in the form of nitrogen oxide (NO). Nitrogen dioxide $\left(\mathrm{NO}_{2}\right)$, which is the focus of concern in terms of adverse health effects, quickly forms by a photochemical reaction in the ambient air in the presence of $\mathrm{NO}$ and ozone $\left(\mathrm{O}_{3}\right)$. However, primary $\mathrm{NO}_{\mathrm{x}}$ emissions from more technologically advanced heavy-duty diesel engines with aftertreatment devices may contain a much greater percentage of $\mathrm{NO}_{2}$ in exhaust emissions. Thus, $\mathrm{NO}$ and $\mathrm{NO}_{2}$ will be present in varying concentrations in the near-road microenvironment.

Sulfur dioxide Although motor vehicles emit sulfur dioxide $\left(\mathrm{SO}_{2}\right)$ and other sulfur-containing compounds, traffic sources typically make only small contributions to ambient concentrations. In addition, the introduction of low-sulfur fuels in the USA and other countries to allow for the use of after-treatment devices in diesel vehicles should further reduce $\mathrm{SO}_{2}$ emissions. Therefore, this pollutant is not commonly monitored in near-road applications. However, the monitoring of $\mathrm{SO}_{2}$ may be useful near other types of transportation facilities, such as airports, railway yards, and seaports, as sources at these locations may still burn high sulfur fuels. In addition, it may be useful to measure this pollutant (or other sulfur-containing compounds) in specific situations to identify the influence of other sources at the monitoring site, such as power generation or ship emissions.

Ozone Ozone is not directly emitted from motor vehicles, and $\mathrm{O}_{3}$ measurements are not typically collected for nearroad applications. However, the presence of elevated NO concentrations in the near-road microenvironment may lead to lower concentrations due to "ozone scavenging" as part of the formation of $\mathrm{NO}_{2}$ from $\mathrm{NO}$ and $\mathrm{O}_{3}$. Thus, $\mathrm{O}_{3}$ measurements may be useful under select circumstances as support for health studies investigating the role of $\mathrm{O}_{3}$ and other co-pollutants on adversely affecting public health given the potentially lower concentrations of this pollutant relative to other pollutants in this microenvironment.

Lead Before the introduction of unleaded gasoline throughout much of the world, motor vehicle lead $(\mathrm{Pb})$ emissions were a major public health concern. While $\mathrm{Pb}$ is no longer added to gasoline in many countries, motor vehicle fuels still contain trace amounts of $\mathrm{Pb}$ from crude oil. Lead is also present in trace amounts in lubricating oil. Other sources that may contribute to ambient $\mathrm{Pb}$ concentrations in the near-road environment include brake wear, tire wear, and the degradation of wheel weights used for aftermarket tire balancing. Re-suspended road dust may also contain $\mathrm{Pb}$ from historically deposited industrial or mobile source emissions.

Particulate matter Motor vehicles emit significant amounts of PM through combustion, brake wear, and tire wear, and they may also contribute to elevated near-road PM concentrations by re-suspending dust present on the road surface. In the USA, the NAAQS regulates ambient concentrations of $\mathrm{PM}<10 \mu \mathrm{m}$ in diameter $\left(\mathrm{PM}_{10}\right)$ and $\mathrm{PM}<2.5 \mu \mathrm{m}$ in diameter $\left(\mathrm{PM}_{2.5}\right)$. Both of these PM size fractions are emitted from motor vehicles. In general, PM emitted by combustion will be in the $\mathrm{PM}_{2.5}$ size fraction. Since combustion-emitted particles are typically present at $<0.1 \mu \mathrm{m}$ in diameter, these emissions tend to contribute little to ambient $\mathrm{PM}_{2.5}$ mass concentrations, but they do contribute significantly to PM number concentrations and may impact the chemical composition of the $\mathrm{PM}_{2.5}$ mass collected near the road relative to urban background 
conditions. Accumulation mode PM formed from motor vehicle combustion emissions may also impact $\mathrm{PM}_{2.5}$ mass concentrations further downwind from the road. Particulate matter emitted through mechanical processes (brake wear, tire wear, re-suspended road dust) will tend to be in the $\mathrm{PM}_{10}$ size fraction and can lead to elevated mass concentrations. As a result, both $\mathrm{PM}_{10}$ and $\mathrm{PM}_{2.5}$ mass measurements may be useful for near-road applications with the expectation of higher impacts on $\mathrm{PM}_{10}$ mass as opposed to $\mathrm{PM}_{2.5}$ mass.

Most $\mathrm{PM}_{10}$ and $\mathrm{PM}_{2.5}$ mass measurements use filterbased, gravimetric analyses over a 24-h sample collection period. However, diurnal variations in traffic and meteorology can have a tremendous impact on near-road air quality that may not be identifiable in 24-h average measurements. Therefore, continuous PM measurements provide useful information for near-road applications, although care must be taken in choosing a sampling method. Optical PM mass samplers typically cannot detect particles less than approximately $0.2-0.5 \mu \mathrm{m}$ in diameter and, consequently, these measurement devices may not capture a significant amount of the PM mass related to primary motor vehicle combustion emissions. In addition, some continuous PM samplers heat the inlet air prior to analysis. Since motor vehicle PM emissions contain a significant amount of semi-volatile organic compounds, these samplers can underestimate the PM mass in the near-road environment by volatilizing the organic PM prior to collection in the sampler.

\section{Unregulated pollutants}

In addition to criteria pollutants, motor vehicles emit a large number of other compounds which can cause adverse health effects. These are often characterized as air toxics or hazardous air pollutants. A discussion and listing of potential air toxics of concern for near-road monitoring can be found in the U.S. Environmental Protection Agency's (EPA) Mobile Source Air Toxics (MSAT) Rule (U.S. EPA 2007). These pollutants include volatile organic compounds (VOCs), aldehydes, and organic and inorganic PM constituents. The reasons for monitoring these pollutants in a near-road program include concerns over adverse human health effects, ecological effects, and the evaluation of the effectiveness of mobile source control programs. This section discusses potential monitoring activities for a number of classes of air toxic compounds, but a discussion of all potential air toxic compounds identified in the MSAT rule is beyond the scope of this document.

Volatile organic compounds These air toxics are found in the gas phase in ambient air. Typical VOCs of concern for near-road monitoring include, but are not limited to, benzene, toluene, ethylbenzene, xylenes, and styrene. A more detailed listing of potential VOCs of health concern is included in the MSAT Rule. Volatile organic compounds are typically measured by the collection of ambient air using evacuated canister sampling and subsequent analysis on a gas chromatograph (GC). Another class of VOCs, carbonyls, is typically collected in another way, as described in the next section. For evacuated canister sampling, the sample collection time can vary from instantaneous grab sample to averaging times of more than $24 \mathrm{~h}$ depending on the collection orifice used. As discussed for PM sampling, shorter averaging times can be important to discern the impacts of varying vehicle and environmental conditions on near-road air quality. Auto-GCs can be used to measure select VOC pollutant concentrations semicontinuously at a monitoring site. A number of manufacturers also advertise semi-continuous analyzers for one or more VOCs of interest using various GC technologies.

Aldehydes Aldehydes emitted from motor vehicles include, but are not limited to, formaldehyde, acetaldehyde, and acrolein. A more detailed listing of aldehydes with potential health concerns is included in the MSAT Rule. Aldehydes are typically measured using cartridges containing dinitrophenyl hydrazine (DNPH). However, other methods, including evacuated canisters and cartridges with dansylhydrazine (DNSH), have been used to measure ambient concentrations of some of these compounds. Sample collection periods of $24 \mathrm{~h}$ or more are typically required for assessing ambient aldehyde concentrations although a few manufacturers advertise semi-continuous analyzers for select compounds.

Particulate matter constituents The PM present near roadways contains a number of organic and inorganic constituents that may pose a public health risk. Organic PM samples are most often collected on filters backed by a cartridge to collect the gas-phase constituents. Sample collection methods typically consist of high-volume samplers to maximize the amount of PM mass obtained for detailed chemical and physical analysis; thus, collection times can be from $24 \mathrm{~h}$ to over a week to collect an ample amount of mass. Inorganic PM samples are also usually collected on filters using high-volume samplers and longer sampling times in order to collect sufficient mass for elemental analyses. A detailed listing of organic and inorganic PM compounds of health concern is included in the MSAT Rule. In addition, detailed speciation of organic and elemental PM compounds present in near-road samples can be useful in conducting or evaluating source apportionment studies to estimate the impacts of traffic emissions on near-road PM concentrations, although the long sample averaging times required for this analysis may limit the 
ability to discern differences in vehicle activity on PM organic and inorganic air quality impacts.

\section{Surrogate measurements}

A number of surrogate measurements can also be considered to assist in interpreting traffic emission impacts on near-road air quality and to determine possible causes of adverse health effects. One common surrogate has been the use of $\mathrm{CO}$ to represent the impacts of other non-reactive gas emissions that are more difficult to measure from motor vehicles. While studies do show that $\mathrm{CO}$ and other nonreactive VOC concentrations tend to correlate in the nearroad environment, the magnitude of VOC concentrations relative to $\mathrm{CO}$ concentrations may be difficult to discern because of varying impacts from control strategies and emission sources. Regulations that have led to reductions in $\mathrm{CO}$ emissions may not equally affect VOC emission rates. In addition, $\mathrm{CO}$ is emitted by fuel combustion, whereas VOCs are emitted from both combustion and evaporation processes. Carbon monoxide may also not be a consistent surrogate for roadways dominated by heavy-duty diesel vehicle traffic due to low emission rates of this pollutant from these vehicles.

Other surrogate measurements focus on PM constituents that are primarily emitted from motor vehicles and which may pose a public health concern. These surrogate measurements are discussed in the following sections.

\section{Particulate matter number concentration}

As previously discussed, PM emitted through the combustion process occurs primarily in the ultrafine size range (i.e., $<0.1 \mu \mathrm{m}$ in diameter); thus, the impact on PM mass may be negligible. However, emissions of these small particles occur in extremely large quantities; therefore, PM number concentration measurements often provide a good indication of primary PM exhaust emissions from motor vehicles. In addition, several health studies suggest that ultrafine particles may lead to adverse health effects, as identified in the near-road literature. A number of devices exist to measure PM number concentrations, ranging from inexpensive industrial hygiene monitors to research-grade ambient air monitors. Most of these devices can provide number concentration measurements in near real-time, although the range of particle sizes and concentrations detected do vary. When measurements from different devices are compared, any differences in particle size ranges detected must be noted.

Black (or elemental) carbon Black carbon (BC), often referred to as "soot," is a common constituent emitted from motor vehicles. Another measurement is elemental carbon (EC), which is detected using different techniques. Both BC and $\mathrm{EC}$ are operationally defined and represent the graphitic-containing portion of PM. Although BC and EC are often associated with emissions from heavy-duty diesel engines, a portion of all motor vehicle combustion emissions contains these constituents. Other sources of $\mathrm{BC}$ or EC exist in urban areas, but emissions from motor vehicles usually dominate these sources in terms of nearroad air quality, thus making $\mathrm{BC}$ or EC measurements a useful parameter for identifying impacts from motor vehicle emissions.

\section{Site location considerations}

The complexity of urban land use makes the process of selecting appropriate monitoring sites an extremely important consideration for near-road assessments. This complexity is important when the objective is to understand historical monitoring data. Factors such as the type of road, traffic activity patterns, roadway design features, and the presence of nearby structures and barriers will influence the transport and dispersion of pollutants emitted by nearby traffic. In addition, the number and location of samplers will affect the type of information obtained and the manner is which the data can be applied to decision-making regarding public health issues. The following sections provide more details on site location issues and logistical considerations for establishing near-road air quality monitoring programs or interpreting near-road monitoring data.

\section{Roadway type}

Most health and air quality studies implicating roadways as a public health concern have generally focused on highways supporting large volumes of traffic. These transportation facilities typically support a large number of passenger cars and large trucks operating at higher speeds during most times of the day. However, most urban highways experience regular periods of congestion during morning and afternoon rush hours at which time vehicles tend to operate at low speeds and/or even idle. On these high-speed highways, motor vehicle emissions occur primarily from fuel combustion, fluid evaporation, brake and tire wear, and re-suspended road dust.

Most urban areas also contain arterial roadways with large volumes of both passenger cars and large trucks, although these roads typically support much lower traffic volumes than highways. Some health studies suggest that residential proximity to arterial traffic emissions may relate to a higher public health risk than highway traffic emissions 
(Reponen et al. 2003). Several factors lead to differences in traffic-generated pollutant emissions between an arterial road and a highway. Vehicles on arterial roads may experience more stop-and-go operations from traffic signals and turning vehicles, which may lead to higher combustion emissions from acceleration and long idling times and more brake and tire wear from acceleration and deceleration. In addition, some vehicles on arterial roads may be operating under cold start conditions, where combustion emissions increase because the vehicle has not been operating for a long enough time to fully heat the catalytic converter (Baldauf et al 2005). Under these conditions, vehicle emissions tend to be higher, and the types and ratios of VOC and PM compounds emitted may be different from higher volume roadways. Thus, near-road monitoring around differing road types yield differing air quality measurements.

\section{Traffic volumes and modes of operation}

There is no known threshold for total traffic volume, or the percentage of large trucks, below which near-road populations are protected from adverse health effects or pollutant concentrations are maintained below NAAQS levels. Traffic emissions depend on a number of factors, including traffic activity and traffic volume, and both of these factors must be considered when data are interpreted or near-road monitoring sites are established.

\section{Roadway design}

Roadway design can influence the amount of emissions generated from motor vehicles and the transport and dispersion of the pollutants away from the road. Road grades, ramps, intersections, and traffic merge locations can all impact on the type and amount of vehicle emissions. Road grades create an increased load on vehicles ascending the grade, leading to increased exhaust emissions and potential tire wear, while vehicles descending the grade likely experience increased brake emissions. The presence of ramps, intersections, and lane merge locations can also lead to increased brake wear emissions and idling vehicle conditions due to increased congestion. The type of pavement on the road may also affect the amount of wear emissions and re-suspended road dust, as asphalt pavements also emit small levels of VOCs.

The topography around the roadway influences pollutant transport and dispersion away from the road. At-grade roadways will experience the least amount of resistance to pollutant dispersion if no other structures exist near the road. However, cut section roads, where the roadway is below ground-level and bordered by either vertical or sloped cut walls, increase the number of vortices created by wind flow into and along the cut section roadway, thereby increasing pollutant dispersion. In addition, as winds flow up and out of the cut section, the plume off the roadway may be more elevated than under an at-grade condition. Elevated roadways may concentrate pollutants near the road or enhance pollutant dispersion away from the road depending on design. The amount of mixing will vary if the road is elevated by a bridge or solid fill material. Figure 1 shows an example from a wind tunnel study comparing roadway design configurations and changes in near-road air pollutant concentrations to illustrate these effects.

Regardless of the roadway design, the activity of vehicles on the road induce turbulence at the point of pollutant emission, leading to enhanced pollutant mixing. In addition, the elevated temperature of exhaust emissions enhance thermal buoyancy in the plume, providing an initial mixing zone for vehicle-emitted pollutants that depends on the number, type, and speed of vehicles on the road. The more turbulence present, the more initial dilution of pollutants will occur. The initial mixing and turbulence effects will impact on decisions regarding monitor siting, as discussed in more detail in a later section of this paper.

\section{Roadside structures}

In addition to topographic feature changes near the road, structures may be present that impact pollutant transport and dispersion. These structures include noise barriers, vegetation, and buildings. Physical barriers affect pollutant concentrations around the structure by blocking initial dispersion and increasing turbulence and initial mixing of the emitted pollutants. Figure 2 illustrates the potential effects of roadside barriers from field measurements taken from an open field, from behind a noise barrier, and from

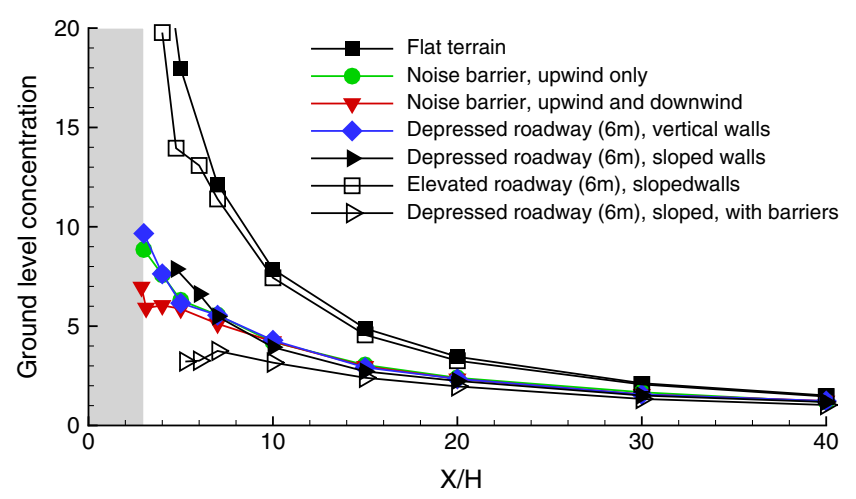

Fig. 1 Wind tunnel study results comparing downwind air pollutant concentrations from a road at-grade with no obstructions to airflow with roadway configurations containing varying topography and roadside structures. The distance downwind is expressed in multiples of the height of the noise barrier studied ( $6 \mathrm{~m}$ for this study). The ground-level concentrations have been non-dimensionalized as CULX/ $Q y$ where $C$ is the measured concentration, $U$ is the wind speed at a height of $30 \mathrm{~m}, L x$ is the width of the road, and $Q y$ is the pollutant emission rate per unit length of roadway. These results are for winds perpendicular to the road (Heist et al. 2007) 


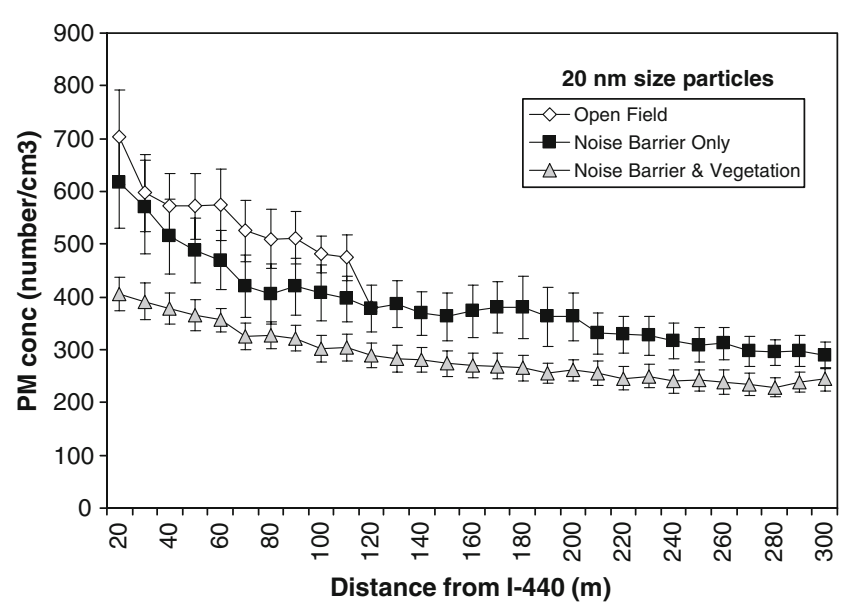

Fig. 2 Mobile monitoring measurements of the number of $20-\mathrm{nm}$ sized particulate matter $(P M)$ present at varying distances from a 125,000 average annual daily traffic (AADT) highway for an at-grade road: no obstructions (open field), behind only a noise barrier (noise barrier only), behind a noise barrier with mature vegetation stands (noise barrier \& vegetation). Bars 95\% Confidence intervals for each distance (Baldauf et al. 2008b).

behind a noise barrier and vegetation stands. A description of the role of common barriers and structures in urban environments follows.

Noise barriers Noise barriers reduce noise levels from traffic by blocking and deflecting sound waves. These barriers also affect air pollutant dispersion, leading to increased vertical mixing due to the upward deflection of air flow caused by the structure. Studies suggest that this upward deflection of air creates a recirculation cavity downwind of the barrier containing a well-mixed, and potentially lower, zone of pollution concentrations. However, noise barriers adjacent to a roadway may also inhibit air movements off the road, leading to elevated on-road pollutant concentrations (Bowker et al. 2007; Baldauf et al. 2008b).

Vegetation Vegetation stands will also affect near-road pollutant concentrations. The complex and porous structure of tree limbs and leaves increase air turbulence and promote mixing and dispersion. Trees and other vegetation also reduce pollutant concentrations by enhancing the deposition of certain pollutants, notably PM components. Variables such as the type of vegetation, plant height, and vegetation thickness will likely influence the extent of mixing and deposition experienced at the site, although the specific relationships of these factors have not been identified (Heichel and Hankin 1976; Munch 1993; Bussotti et al. 1995; Heath et al. 1999; Beckett et al. 2000; Bowker et al. 2007; Baldauf et al. 2008b).

Buildings Nearby buildings and other related structures also affect air transport and dispersion. The presence of large, solid structures impact on air flow, creating eddies and wake regions similar to those described for noise barriers. The effect on air pollutant transport and dispersion will depend on the number and type of structures present. Isolated, detached structures will likely impact only on pollutant concentrations in close proximity to the structure. However, large numbers of buildings may create funneling effects that can actually concentrate pollutants at certain locations. This phenomenon is often referred to as the "street canyon" effect. Buildings also provide surface areas for particle deposition.

\section{Monitor siting considerations}

When monitoring sites are being assessed for their suitability to determine the impact of traffic emissions on near-road air quality, a number of factors need to be considered, including distance from the road, upwind/ background monitoring, horizontal spacing, and the need for vertical measurements.

Distance from the road Results from previous near-road monitoring studies show that air pollutant concentration gradients are quite steep near the road. Many of these studies suggest that traffic-generated pollutants decrease exponentially with distance from the road, with most showing that background pollutant levels are reached within 200-500 m from the road. However, the magnitude and shape of this curve depends on source characteristics, meteorology, and roadway design features, as previously discussed. Figures 1 and 2 demonstrate that the changing concentrations with distance tend to be exponential; however, the shape and magnitude of these curves can change, especially with changes in roadway configuration and the presence of roadside structures.

To account for this decrease in pollutant concentrations in the near-road microenvironment, many studies utilize multiple monitoring stations at varying distances from the road, with the highest density of monitors within the first $100 \mathrm{~m}$ from the road. If resource limitations prevent the establishment of multiple monitoring sites, a distance most representative of population exposures may be more appropriate. A minimum distance of $10-20 \mathrm{~m}$ from the road should be considered in order to minimize the influence of vehicle-induced turbulence on the concentration variability of pollutant measurements.

Upwind/background monitoring Collecting upwind and background air quality measurements may be useful in assessing traffic emission impacts from a roadway. Paired monitors on either side of a road can limit the influence of changing wind directions when interpreting near-road air 
quality data. When winds shift in direction, an upwind and downwind pair of monitors will still remain.

When upwind monitoring locations are being considered, care must be taken in ensuring that this site is an appropriate distance from the road. Vehicle-induced turbulence may allow traffic-generated pollutants to "meander" upwind, resulting in elevated pollutant concentrations at distances as far as 50-100 $\mathrm{m}$ upwind of the road (Venkatram et al. 2007).

Horizontal spacing Since topographic features influence pollutant concentrations near roads, multiple samplers at equal distances from the road, but under varying topographic or roadside structure conditions, can be used to confirm the effect of these varying conditions. In addition to fixed-site sampling at multiple locations, temporary or mobile monitoring using instrumented vehicles may be considered for short-term monitoring comparisons.

Vertical measurements As previously discussed, topographic features and roadside structures also enhance vertical mixing of the plume emitted by traffic sources. Concentration measurements at multiple elevations can assess the variability in plume height with changing traffic, meteorology, and roadway designs. In addition, vertical measurements may be useful for identifying pollutant concentrations at air inlet heights for nearby buildings, such as schools or residences.

\section{Summary}

This paper describes factors to consider when implementing a near-road air quality monitoring program or interpreting data collected at existing monitoring sites. Care must be taken in determining the pollutants of interest for both air quality and health assessments. Planners and data analysts need to evaluate the influence of the roadway type, design, and presence of near-road structures on the potential transport and dispersion of traffic-emitted pollutants on air quality and health evaluations. Further near-road studies will increase our understanding of roadways as emission sources impacting on local- to regional-scale pollutant concentrations. This increased understanding will, in turn, allow near-road monitoring, as a component of ambient air monitoring strategy, to be more appropriately included in overarching air quality management practices.

Open Access This article is distributed under the terms of the Creative Commons Attribution Noncommercial License which permits any noncommercial use, distribution, and reproduction in any medium, provided the original author(s) and source are credited.

\section{References}

Adar SD, Kaufman JD (2007) Cardiovascular disease and air pollutants: evaluating and improving epidemiological data implicating traffic exposure. Inhal Toxicol 19[Suppl 1]:135149. doi: $10.1080 / 08958370701496012$

Baldauf RW, Crews W, Snow R, Gabele P (2005) Criteria and air toxic emissions from in-use, low emission vehicles. J Air Waste Manage Assoc 55:1263-1268

Baldauf RW, Thoma E, Hays M, Shores R, Kinsey J, Gullett B, Kimbrough S, Isakov V, Long T, Snow R, Khlystov A, Weinstein J, Chen F, Seila R, Olson D, Gilmour I, Cho S, Watkins N, Rowley P, Bang J (2008a) Traffic and meteorological impacts on near road air quality: summary of methods and trends from the Raleigh Near Road Study. J Air Waste Manage Assoc 58:865-878

Baldauf RW, Khlystov A, Isakov V, Thoma E, Bowker GE, Long T, Snow R (2008b) Impacts of Noise Barriers on Near-Road Air Quality. Atmos Environ 42:7502-7507

Beckett JP, Freer-Smith PH, Taylor G (2000) Effective tree species for local air quality management. Arboriculture 26(1):12-19

Bowker GE, Baldauf RW, Isakov V, Khlystov A, Petersen W (2007) Modeling the effects of sound barriers and vegetation on the transport and dispersion of air pollutants from roadways. Atmos Environ 41:8128-8139. doi:10.1016/j.atmosenv.2007.06.064

Bussotti F, Grossomi P, Batistoni P, Ferretti M, Cenni E (1995) Preliminary studies on the ability of plant barriers to capture lead and cadmium of vehicular origin. Aerobiologia 11(1):11-18. doi:10.1007/BF02136139

Finkelstein MM, Jerrett M, Sears MR (2004) Traffic air pollution and mortality rate advancement periods. Am J Epidemiol 160:173177. doi:10.1093/aje/kwh181

Gauderman WJ, Avol E, Lurmann F, Kuenzli N, Gilliland F, Peters J, McConnell R (2005) Childhood asthma and exposure to traffic and nitrogen dioxide. Epidemiology 16(6):737-743. doi:10.1097/ 01.ede. 0000181308.51440 .75

Harrison RM, Tilling R, Callen Romero MS, Harrad S, Jarvis K (2003) A study of trace metals and polycyclic aromatic hydrocarbons in the roadside environment. Atmos Environ 37:23912402. doi:10.1016/S1352-2310(03)00122-5

Heath BA, Maughan JA, Morrison AA, Eastwood IW, Drew IB, Lofkin M (1999). The influence of wooded shelterbelts on the deposition of copper, lead, and zinc at Shakerley Mere, Cheshire, England. Sci Total Environ 235(1-3):415-417

Heichel GH, Hankin L (1976) Roadside coniferous windbreaks as sinks for vehicular lead emissions. J Air Pollut Control Assoc 26 (8):767-770

Heist DK, Perry SG, Brixey LA, Bowker GE (2007) Wind tunnel simulations of pollution from roadways. In: D.K. Proc Int Workshop Physical Model (PHYSMOD 2007). Orléans, France, pp 63-68

Kalthoff N, Baumer D, Corsmeier U, Kohler M, Vogel B (2005) Vehicle-induced turbulence near a motorway. Atmos Environ 39:5737-5749. doi:10.1016/j.atmosenv.2004.06.048

Kim JJ, Smorodinsky S, Lipsett M, Singer BC, Hogdson AT, Ostro B (2004) Traffic-related air pollution near busy roads: the East Bay Children's Respiratory Health Study. Am J Respir Crit Care Med 170(5):520-526. doi:10.1164/rccm.200403-281OC

McConnell R, Berhane K, Yao L, Jerrett M, Lurmann F, Gilliland F, Kuenzli N, Gauderman J, Avol E, Thomas D, Peters J (2006) Traffic, susceptibility, and childhood asthma. Environ Health Perspect 114(5):766-772

Munch D (1993) Concentration profiles of arsenic, cadmium, chromium, copper, lead, mercury, nickel, zinc, vanadium, and PAH in forest soil beside an urban road. Sci Total Environ 138 (1-3):7-55 doi:10.1016/0048-9697(93)90404-T 
Pearson RL, Wachtel H, Ebi L (2000) Distance-weighted traffic density in proximity to a home is a risk factor for leukemia and other childhood cancers. J Air Waste Manage Assoc 50:175180

Reponen T, Grinshpun SA, Trakumas S, Martuzevicius D, Wang ZM, LeMasters G, Lockey JE, Biswas P (2003) Concentration gradient patterns of aerosol particles near interstate highways in the Greater Cincinnati airshed. J Environ Monit 5(4):557-562. doi:10.1039/b303557c

Samal MT, Islam T, Gilliland FD (2008) Recent evidence for adverse effects of residential proximity to traffic sources on asthma. Curr Opin Pulm Med 14(1):3-8. doi:10.1097/MCP.0b013e3282f1987a

Samet JM (2007) Traffic, air pollution, and health. Inhal Toxicol 19:1021-1027 doi:10.1080/08958370701492706
U.S. Environmental Protection Agency (EPA) (2007) Control of hazardous air pollutants from mobile sources. Report 72 FR 8428: final regulatory impact analysis. EPA, Washington D.C. Available at: http://www.epa.gov/otaq/regs/toxics/420r07002.pdf

Venkatram A, Isakov V, Thoma E, Baldauf RW (2007) Analysis of air quality data near roadways using a dispersion model. Atmos Environ 41:9481-9497. doi:10.1016/j.atmosenv.2007.08.045

Wilhelm M, Ritz B (2003) Residential proximity to traffic and adverse birth outcomes in Los Angeles County, California, 1994-1996. Environ Health Perspect 111:207-216

Zhu Y, Hinds WC, Kim SK, Shen S, Sioutas C (2002) Study of ultrafine particles near a major highway with heavy-duty diesel traffic. Atmos Environ 36:4323-4335. doi:10.1016/S1352-2310 (02)00354-0 